\title{
The influence of behavioural intention on third-party e-commerce payment
}

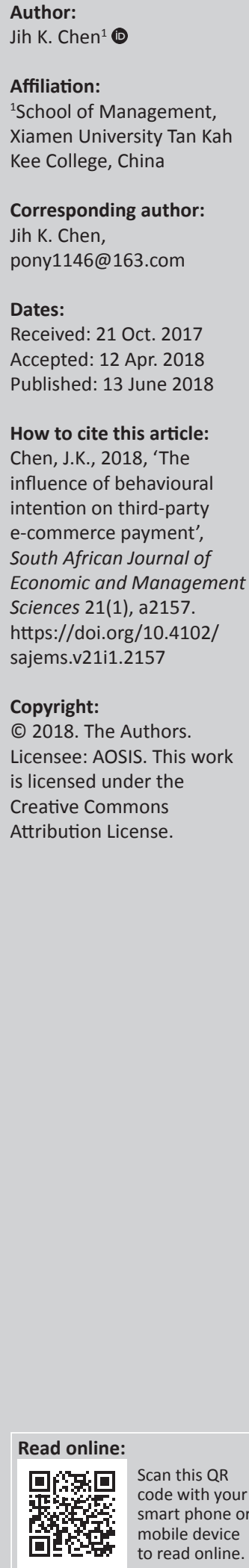

Background: Third-party e-commerce payment has been used by many businesses and consumers, enabling customers to easily access the payment platform during e-commerce transactions. Thus, the emergence of such new technology has become a major topic for organisations to study factors that have influenced the people's adoption and acceptance of new technology as well as mutual influence.

Setting: The Technology Acceptance Model is one of the most studied models of behavioural intention to use new information technology.

Aim: However, in terms of the causal relationship of variables in the model, one variable is considered independent, ignoring the possibility of mutual influence, and many samples are required for statistical empirical research. This study aims to resolve these above two deficiencies.

Methods: This study adopts the Decision-Making and Trial Evaluation Laboratory method, and applies the latest Technology Acceptance Model (TAM3) to examine.

Results: The results found several extra causal relationships which are not present in the TAM3 model, and understood that Experience and Computer Playfulness are the driving factors of third-party e-commerce payment, and Computer Anxiety is the core factor.

Conclusion: The feasibility of this approach was demonstrated through an empirical study, and these results could be used to guide management direction and marketing strategy.

\section{Introduction}

With the continued development of the Internet, traditional business models have changed significantly. For the flourishing development of e-commerce, online payment plays a key role because trust establishment is difficult as both parties of the transaction are 'virtual' individuals. Third-party e-commerce payment is the most successful model at present. Compared to traditional payment methods, third-party e-commerce payment offers advantages such as efficiency (saving transaction costs and time), convenience (paying bills at any time and any place), and flexibility (providing payment control and management) (Huang, Dai \& Liang 2014). Additionally, it allows clients to transfer money into an online account and make payments from that account without exposing their real credit card or bank account information (Jim 2007). With the help of operational convenience and functional expansion, guaranteed intermediary third-party payment methods have effectively solved the problem of credibility, logistics, and cash flow. This method is now used by many businesses and consumers, enabling customers to easily access the payment platform during e-commerce transactions.

There are many available online third-party e-commerce payment services. Well-known systems include PayPal, which cooperates with the eBay online marketplace, and Alipay, which cooperates with Taobao.com. New third-party e-commerce payment services have been developed and are used on various websites. The emergence of acceptance of such new information technology (IT) is a major focus of researchers studying factors that influence the adoption and acceptance of new IT and mutual influence.

The Technology Acceptance Model (TAM) is one of the most studied models of behavioural intention to use new IT. TAM is a theory of reasoned action and was applied to user information system acceptance by Davis (1989). TAM can allow study of the effects of external variables between perceived usefulness, perceived ease of use, and behavioural intention, and thus can guide the implementation and application of a technology system (Riemenschneider, Harrison \& Mykytn 2003). For this reason, TAM has been widely used in efforts to promote the 
acceptance of various information technology, for example e-mail systems by Szajna (1996), Internet banking by Lai and $\mathrm{Li}$ (2005), customer usage and consumer-to-consumer behaviour (C2C) by He, Lu and Zhou (2008), broadband by Irani, Dwivedi and Williams (2009), online games by Zhu, Lin and Hsu (2012), social media by Dutot (2014), and retail services of an Internet bank in South Africa by Maduku (2016).

However, since the establishment of TAM theory, scholars have expanded and modified this prototype from TAM1, TAM2, to TAM3, for improved explanatory ability. Many scholars have adopted the recently developed TAM3 model to study the influence of behavioural intention. For example, Agudo-Peregrina, Hernández-García and Pascual-Miguel (2014) proposed a TAM3-based model with two additional variables: personal innovativeness and perception which enable study of the factors influencing the acceptance of e-learning systems. Akman and Mishra (2015) examined diversity between public and private sector establishments in Green IT adoption using a TAM3 model. Ooi and Tan (2016) proposed an extension of TAM3 that included mobile usefulness and mobile ease of use to determine smartphone credit card adoption. Mathu and Tlare (2017) explored the influence of IT adoption of small and medium enterprises (SMEs) in two provinces of South Africa, and ascertained the IT influence of supply chain integration and collaboration of the SMEs. Here, this study aims to adopt the TAM3 model to analyse the influence of behavioural intention for third-party e-commerce payment.

However, TAM models have two important assumptions and deficiencies: (1) In terms of the causal relationship of variables in the model, one variable is considered independent, ignoring the possibility of mutual influence, and (2) empirical study typically relies on survey questionnaires and hypothesis testing by statistical analysis, requiring many samples. Because some variables do not meet the independent assumption, TAM will not be able to correctly analyse the overall causal relationships, resulting in the wrong conclusion (Lee et al. 2010). Hence, this study adopted a new method, the Decision-Making and Trial Evaluation Laboratory (DEMATEL) method, instead of the statistical analysis method. DEMATEL is an analysis technology for complex problems that applies expert opinions to evaluate the influence level of the mutual interactions of variables to determine the core factor. This approach not only effectively addresses the above-mentioned two deficiencies, but also allows determination of the driving factors and core factors in the acceptance and adoption of behavioural intention for adoption of third-party e-commerce payment technology. These results could be used to guide management direction and marketing strategy.

\section{Development of Technology Acceptance Model}

TAM is a mature model that has been validated in different contexts. This section describes the variation of TAM theory in recent years.

\section{Original and amended Technology Acceptance Model}

The Theory of Reasoned Action (TRA) was one of the first models that studied the acceptance of technology. This model analyses the determinants of conscious behaviour from the perspective of social psychology (Aizen \& Fishbein 1980; Fishbein \& Ajzen 1975). According to this theory, the specific behaviour of a person is determined by their intention to carry out a behaviour, a process called behavioural intention. Davis (1989) adopted and expanded TRA to develop TAM to evaluate people's acceptance of new information technology. TAM maintains that the use of information technology is determined by behavioural intention, and employs two technology acceptance measures to predict system usage: perceived usefulness and perceived ease of use. In this model, both perceived usefulness and perceived ease of use influence attitudes toward a technology, which in turn influences behavioural intention to use the technology.

Davis and Venkatesh (1996) found that attitude toward is only a user emotion, and the preference of information technology cannot completely convey the impact of perceived usefulness and perceived ease of use on behavioural intention. With this argument, Davis and Venkatesh amended the model by abandoning the attitude toward from the original model, as shown in Figure 1.

\section{Technology Acceptance Model 2}

The next extension of TAM, TAM2, was developed by Venkatesh and Davis (2000). TAM2 incorporates additional theoretical constructs spanning social influence processes including image, subjective norm, voluntariness, and experience, and also a cognitive instrumental process including job relevance, output quality, and result demonstrability. These were treated as the determining variables of perceived usefulness, instead of perceived usefulness being only decided by external variables and perceived ease of use in the previous model, as shown in Figure 2.

\section{Unified Theory of Acceptance and Use of Technology model}

Venkatesh et al. (2003) found task-technology fit (TTF), Innovation Diffusion Theory (IDT), TRA, the Theory of

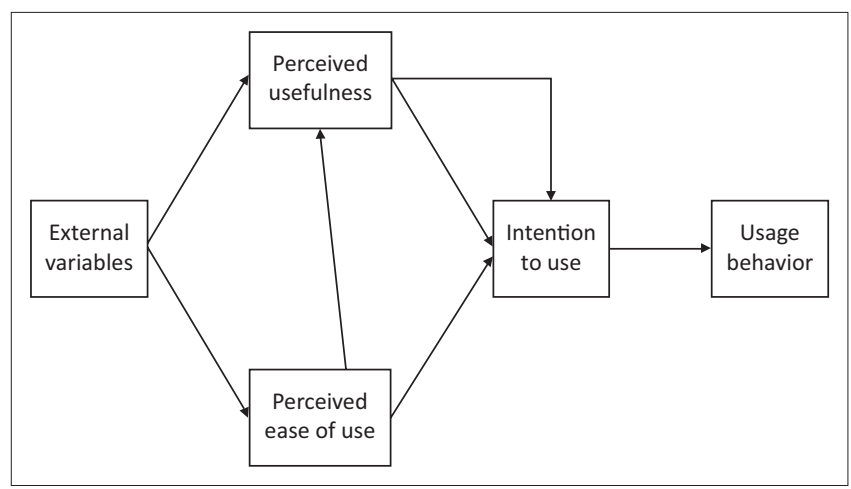

Source: Davis, F.D. \& Venkatesh, V.A., 1996, 'A critical assessment of potential measurement biases in the technology acceptance model: Three experiments', International Journal of Human-Computer Studies 45(1), 19-45. https://doi.org/10.1006/ijhc.1996.0040

FIGURE 1: Technology Acceptance Model 1. 


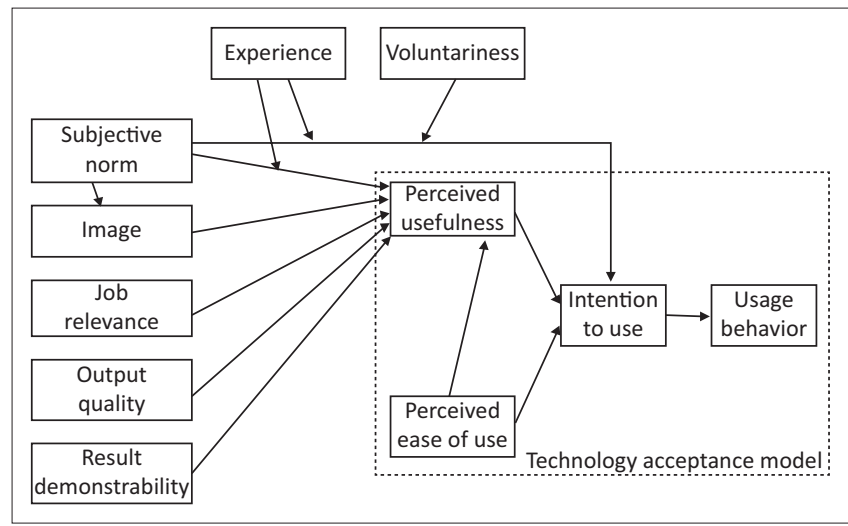

Source: Venkatesh, V. \& Davis, F.D., 2000, 'A theoretical extension of the technology acceptance model: Four longitudinal field studies', Management Science 45(2), 186-204. https://doi.org/10.1287/mnsc.46.2.186.11926

FIGURE 2: Technology Acceptance Model 2.

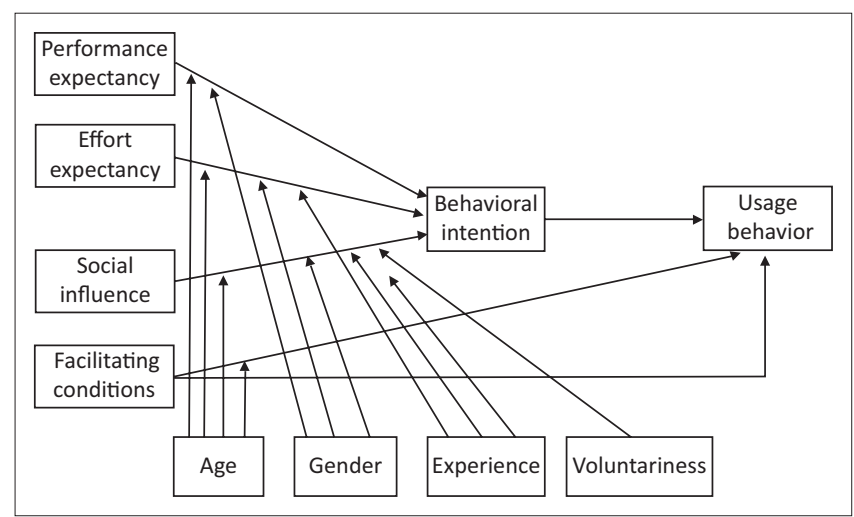

Source: Venkatesh, V., Morris, M.G., Davis, G.B. \& Davis, F.D., 2003, 'User acceptance of information technology: Toward a unified view', MIS Quarterly 27(3), 425-478. https://doi. org/10.2307/30036540

FIGURE 3: Unified Theory of Acceptance and Use of Technology model.

Planned Behaviour (TPB), motivational model (MM), combined TAM and TPB (C-TAM-TPB), model of PC utilisation (MPCU), and Social Cognitive Theory (SCT) also have relevant explanatory ability in different categories. Therefore, these authors integrated these models and proposed a Unified Theory of Acceptance and Use of Technology (UTAUT). UTAUT integrates the arguments of eight models into four core determinants, performance expectancy, effort expectancy, social influence, and facilitating conditions, and four regulated variables, gender, age, experience, and voluntariness, as shown in Figure 3.

\section{Technology Acceptance Model 3}

Venkatesh (2000) developed a model of the determinants of perceived ease of use, which builds on the anchoring and adjustment framing of human decision-making. The anchors suggested by Venkatesh are computer self-efficacy, computer anxiety, computer playfulness, and perceptions of external control. In addition, two system characteristic-related adjustments, perceived enjoyment and objective usability, were suggested to play a role in determining the perceived ease of use after individuals gain experience with a new technology.

Computer self-efficacy is the degree to which an individual believes that they have the ability to perform a specific task

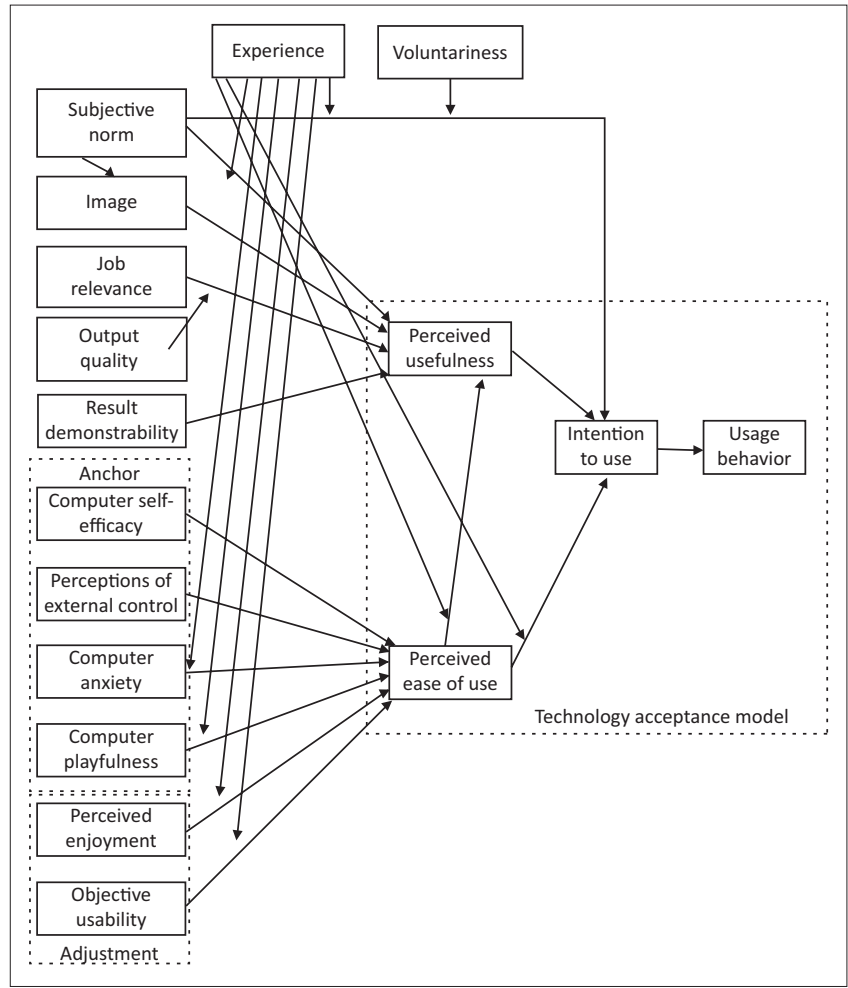

Source: Venkatesh, V. \& Bala, H., 2008, 'Technology Acceptance Model 3 and a research agenda on interventions', Decision Sciences 39(2), 273-315. https://doi.org/10.1111/j.15405915.2008.00192.x

FIGURE 4: Technology Acceptance Model 3.

or job using the computer. Perception of external control is the degree to which an individual believes that organisational and technical resources exist that can support the use of the system. Computer anxiety is the degree of an individual's apprehension, or even fear, when faced with the possibility of using computers. Computer playfulness is the degree of cognitive spontaneity in computer interactions. Perceived enjoyment is the extent to which the activity of using a specific system is perceived to be enjoyable in its own right, aside from any performance consequences resulting from system use. Objective usability is a comparison of systems based on the actual level of effort required to complete specific tasks.

Later, Venkatesh and Bala (2008) combined TAM2 and the model of the determinants of perceived ease of use to develop an integrated model of technology acceptance, TAM3, shown in Figure 4. TAM3 is the latest theoretic framework for analysis of usage behaviour and user acceptance. In the theoretic framework of TAM3, the anchors and adjustments were significant predictors of perceived ease of use. However, the effects of computer anxiety, computer playfulness, perceived enjoyment, and objective usability on perceived ease of use can be influenced by experience. At the same time, experience can affect perceived ease of use toward perceived usefulness and behavioural intention. In addition, output quality does not directly affect perceived usefulness, but instead can influence the effect of job relevance toward perceived usefulness. 


\section{Decision-making and trial evaluation laboratory method}

DEMATEL was developed by the Battelle Memorial Association of the Geneva Research Center (Fontela \& Gabus 1976; Gabus \& Fontela 1973) to study the disjointed and antagonistic phenomena of world societies and search for integrated solutions. In recent years, DEMATEL has been widely adopted because it is useful and practical to visualise the structure of complex causal relationships with matrices or digraphs that portray the contextual relationships between the elements of the system, where a numeral represents the strength of influence. Therefore, DEMATEL can convert the relationship between the effects and causes of criteria into an intelligible structural model of the system. There are several successful applications of this model in many fields. For instance, Chiu et al. (2006) adopted DEMATEL to study marketing strategy based on customer behaviour related to LCD TVs. Lin et al. (2011) used DEMATEL to explore the interrelationships of the core competences in the IC Design Service Company. Fu, Zhu and Sarkis (2012) used DEMATEL to evaluate the influence relationships of green supplier development programmes. Tzeng (2014) explored the subjective factors that parole board members consider in parole decisions by DEMATEL.

Briefly, the structure of DEMATEL is as follows. Suppose that a system contains a set of variables $C=\left\{C_{1}, C_{2}, \ldots, C n\right\}$, and the particular pair-wise relations are determined for modelling with respect to an influence relation. The evaluation and calculation procedure is:

- Evaluate the mutual influence of all variables.

- Integrate the opinions of all experts.

- Establish direct-relation matrix.

- Calculate normalised direct-relation matrix.

- Calculate total-relation matrix.

- Calculate the total influence degree of each variable and the degree of being influenced.

- Calculate the prominence and relation of all variables.

- Indicate the position of each variable on 2D causal diagram.

\section{Evaluate the mutual influence of all variables}

Evaluate the influence relationships among variables by pairwise comparison by using a questionnaire, brainstorming, or professional opinions. The evaluation scales are levels $0,1,2$, and 3 , which respectively represent 'no effect', 'low effect', 'middle effect' and 'high effect'.

\section{Integrate the opinions of all experts}

Arithmetic average or geometric means are usually adopted.

\section{Establish direct-relation matrix}

With the opinion integration of all experts, the direct-relation matrix, $X$, of $n \times n$ can be obtained. In the direct-relation matrix, $X, x_{i j}$ represents the variable, the level of $i$ affects variable $j$, and the diagonal variable $x_{i j}$ of the direct-relation matrix, $\mathrm{X}$ is set to 0 .

$$
\mathrm{X}=\left[\begin{array}{cccc}
0 & \mathrm{x}_{12} & \ldots & \mathrm{x}_{1 \mathrm{n}} \\
\mathrm{x}_{21} & 0 & \ldots & \mathrm{x}_{2 \mathrm{n}} \\
\vdots & \vdots & \ddots & \vdots \\
\mathrm{x}_{\mathrm{n} 1} & \mathrm{x}_{\mathrm{n} 2} & \ldots & 0
\end{array}\right]
$$

\section{Calculate normalised direct-relation matrix}

The method of normalised direct-relation matrixes uses the biggest sum of the row vector as the normalised base, set:

$$
\lambda=\max _{1 \leq i \leq n}\left(\sum_{j=1}^{n} x_{i j}\right)
$$

From the calculation of Equation 2 and Equation $3, \lambda$ is divided by the direct-relation matrix, $X$, to obtain the normalised direct-relation matrix, $\mathrm{N}$.

$\mathrm{N}=\frac{X}{\lambda}$

[Eqn 3]

\section{Calculate total-relation matrix}

The total-relation matrix, T, can be obtained from Equation 4:

$$
\mathrm{T}=\operatorname{limit}_{\mathrm{w} \rightarrow \infty}\left(N+N^{2}+\ldots \ldots+N^{w}\right)=N(I-N)^{-1}
$$

I is an identity matrix.

\section{Calculate the total influence degree of each variable and the degree of being influenced}

Set $t_{i j}$ as the variable of the total-relation matrix, $T$, and $i$ and $j$ from 1 to $n$. The total influence degree of each variable and the degree of being influenced can be calculated from Equation 5 and Equation 6. Set $D_{i}$ as the sum of row $i$, which represents the variable $i$, and is the cause that affects the sum of other variables. $R_{i}$ is the sum of column $j$, which represents the variable $j$, and is the result and the sum of being affected by other variables. $D_{i}$ and $R_{i}$ include direct and indirect influences.

$$
\begin{aligned}
& D_{i}=\sum_{j=1}^{n} t_{i j}(i=1,2, \ldots ., n), \\
& R j=\sum_{j=1}^{n} t_{i j}(j=1,2, \ldots, n),
\end{aligned}
$$

\section{Calculate the prominence and relation of all variables}

Define $D_{k}+R_{k}$ as the prominence, and set $k$, $i$ and $j$ to range from 1 to $n$, which shows the overall level of this variable being affected and its influence on others. This score shows the core level of variable $k$ in this case. $D_{k}-R_{k}$ is defined as the relation, which means the gap level of the variable being affected and its influence on others. 


\section{Indicate the position of each variable on 2D causal diagram}

Prominence is used as the $X$ axis and relation is used as the $Y$ axis, and the mean of prominence and relation can be divided into four quadrants. After separate calculation of the coordinate score $\left(D_{k}+R_{k}, D_{k}-R_{k}\right)$ of various variables, they can be drawn in a 2D causal diagram. When the $D_{k}-R_{k}$ score is positive, the variable $\mathrm{k}$ is attributed as a cause attribute; if the $D_{k}-R_{k}$ score is negative, the variable $k$ is attributed as an effect attribute. After construction of the $2 \mathrm{D}$ causal diagram and plotting the coordinate score $\left(D_{k}+R_{k^{\prime}}\right.$ $D_{k}-R_{k}$ ) of various variables, it can be seen that if $D_{k}-R_{k}$ is negative and the score of $D_{k}+R_{k}$ is very small, the variable $\mathrm{k}$ is more independent, and it is an effect attribute and there are fewer variables that affect the variable. If $D_{k}-R_{k}$ is negative and the score of $D_{k}+R_{k}$ is very big, it means that the variable $\mathrm{k}$ is the core factor that must be solved or managed; however, it is not required to directly improve this variable. When the $D_{k}-R_{k}$ is positive and the score of $D_{k}+R_{k}$ is very small, this means that the variable $\mathrm{k}$ is also independent, but it can affect a few other variables and sometimes it can be used to solve or manage. If $D_{k}-R_{k}$ is negative and the score of $D_{k}+R_{k}$ is very big, it means that the variable $\mathrm{k}$ is the driving factor to solve or manage the core problem, and should be listed as the priority.

Therefore, DEMATEL can evaluate the interaction influence level among variables and represent complex causal relationships among variables in a visible structural model. This reveals the driving factors of the core problem in complex systems, providing valuable insight for problemsolving.

\section{Case study}

\section{Research design}

To analyse the influence of usage behavioural intention on third-party e-commerce payment services, this study approached six managers and cadres staffs of industry and eight users with rich experiences in third-party e-commerce payment services from three different cities (Xiamen, Guangzhou, and Shanghai). A total of 30 experts assessed the mutual influence of each variable in TAM3 (a total of 17 variables) and separately scored the influence level of each variable from no influence (0) to high influence (3). DEMATEL was adopted to analyse the causal relationships and interaction influence level among these 17 variables of TAM3.

\section{Analysis and result}

According to the arithmetic average, we collected information and reached a conclusion after integrating the assessments from the 30 experts. We then established a direct-relation matrix, $\mathrm{X}$, according to Equation 1.

According to Equation 2, the biggest sum of the row was obtained as 22.07. As the normalised base, $\lambda$, was divided by the direct-relation matrix according to Equation 3, and to obtain total-relation matrix according to Equation 4 . This is shown in Table 2.

The DEMATEL analysis of a third-party e-commerce payment service uses subjective norm (X3) as the example. It can be seen from Table 2 that subjective norm (X3) directly affects image (X4), with an influence level of 0.100 , subjective norm (X3) directly affects perceived usefulness (X14) with an affect level of 0.121 , and subjective norm (X3) directly affects intention to use (X16) with an influence level of 0.133 . The row and column sum of the total-relation matrix, T, can be calculated from Equation 5 and Equation 6. $\mathrm{D}_{\mathrm{i}}$ is set as the sum of row $\mathrm{i}$, and the represented variable $i$ is the cause and the sum of the effect of the other variables. $R_{j}$ is the sum of column $j$, and the represented variable $\mathrm{j}$ is the effect and is the sum of being affected by other variables. Using subjective norm (X3) as the example: the sum of the influence of subjective norm (X3) on other variables can be calculated from Equation 5: $\mathrm{D}_{3}=0.100+0.121+0.133=0.354$. The sum of the influences of other variables on subjective norm (X3) can be calculated

\begin{tabular}{|c|c|c|c|c|c|c|c|c|c|c|c|c|c|c|c|c|c|}
\hline$T$ & $\mathrm{X} 1$ & $\mathrm{X} 2$ & $\mathrm{X} 3$ & X4 & X5 & X6 & $x 7$ & $\mathrm{X8}$ & X9 & $\mathrm{X} 10$ & $\mathrm{x} 11$ & $\mathrm{X} 12$ & $\mathrm{x} 13$ & X14 & X15 & X16 & X17 \\
\hline $\mathrm{X} 1$ & 0 & 0 & 2.23 & 1.33 & 1.24 & 1.34 & 0.97 & 0 & 0 & 2.50 & 2.30 & 2.20 & 2.50 & 1.42 & 1.78 & 1.32 & 0.94 \\
\hline$x 2$ & 0 & 0 & 2.37 & 0 & 1.32 & 0.72 & 0.61 & 0 & 0 & 0 & 0 & 0 & 0 & 1.34 & 1.51 & 1.43 & 1.13 \\
\hline$x 3$ & 0 & 0 & 0 & 2.24 & 0.45 & 0.68 & 0.79 & 0 & 0 & 0 & 0 & 0 & 0 & 2.20 & 1.32 & 2.30 & 1.22 \\
\hline $\mathrm{X} 4$ & 0 & 0 & 0 & 0 & 0 & 1.28 & 1.08 & 0 & 0 & 0 & 0 & 0 & 0 & 2.10 & 1.26 & 0.87 & 0.94 \\
\hline$\times 5$ & 0 & 0 & 0 & 0 & 0 & 1.33 & 1.67 & 0 & 0 & 0 & 0 & 0 & 0 & 2.10 & 1.53 & 1.42 & 1.23 \\
\hline$x 6$ & 0 & 0 & 0 & 0 & 2.20 & 0 & 1.56 & 0 & 0 & 0 & 0 & 0 & 0 & 2.12 & 1.25 & 1.36 & 1.41 \\
\hline $\mathrm{X7}$ & 0 & 0 & 0 & 0 & 0 & 1.66 & 0 & 0 & 0 & 0 & 0 & 0 & 0 & 2.20 & 1.32 & 0.92 & 1.33 \\
\hline$x 8$ & 0 & 0 & 0 & 0 & 0 & 0 & 0 & 0 & 1.64 & 1.92 & 1.73 & 0 & 0 & 0 & 2.36 & 0 & 0 \\
\hline X9 & 0 & 0 & 0 & 0 & 0 & 0 & 0 & 2.16 & 0 & 1.87 & 1.93 & 0 & 0 & 0 & 2.47 & 0 & 0 \\
\hline X10 & 0 & 0 & 0 & 0 & 0 & 0 & 0 & 1.86 & 1.63 & 0 & 2.12 & 0 & 0 & 0 & 2.26 & 0 & 0 \\
\hline X11 & 0 & 0 & 0 & 0 & 0 & 0 & 0 & 2.16 & 1.87 & 1.75 & 0 & 0 & 0 & 0 & 2.22 & 0 & 0 \\
\hline X12 & 0 & 0 & 0 & 0 & 0 & 0 & 0 & 0 & 0 & 0 & 0 & 0 & 2.22 & 0 & 2.18 & 0 & 0 \\
\hline X13 & 0 & 0 & 0 & 0 & 0 & 0 & 0 & 0 & 0 & 0 & 0 & 1.93 & 0 & 0 & 2.46 & 0 & 0 \\
\hline X15 & 0 & 0 & 0 & 0 & 0 & 0 & 0 & 0 & 0 & 0 & 0 & 0 & 0 & 2.28 & 0 & 2.33 & 1.16 \\
\hline X16 & 0 & 0 & 0 & 0 & 0 & 0 & 0 & 0 & 0 & 0 & 0 & 0 & 0 & 0 & 0 & 0 & 2.35 \\
\hline X17 & 0 & 0 & 0 & 0 & 0 & 0 & 0 & 0 & 0 & 0 & 0 & 0 & 0 & 0 & 0 & 0 & 0 \\
\hline
\end{tabular}


TABLE 2: Total-relation matrix of Technology Acceptance Model 3.

\begin{tabular}{|c|c|c|c|c|c|c|c|c|c|c|c|c|c|c|c|c|c|}
\hline $\mathrm{T}_{\text {CUT- } 0,1}$ & $\mathrm{X} 1$ & $\mathrm{X} 2$ & $\mathrm{X3}$ & $\mathrm{X} 4$ & $\mathrm{X} 5$ & $\mathrm{X6}$ & $\mathrm{X7}$ & $\mathrm{X8}$ & X9 & $\mathrm{X} 10$ & $\mathrm{x} 11$ & $\mathrm{X} 12$ & $\mathrm{x} 13$ & $\mathrm{X} 14$ & X15 & $\mathrm{X} 16$ & $\mathrm{x} 17$ \\
\hline $\mathrm{x} 1$ & 0 & 0 & 0.101 & 0 & 0 & 0 & 0 & 0 & 0 & 0.127 & 0.120 & 0.111 & 0.124 & 0.114 & 0.164 & 0.114 & 0 \\
\hline $\mathrm{x} 2$ & 0 & 0 & 0.107 & 0 & 0 & 0 & 0 & 0 & 0 & 0 & 0 & 0 & 0 & 0 & 0 & 0.105 & 0 \\
\hline$x 3$ & 0 & 0 & 0 & 0.100 & 0 & 0 & 0 & 0 & 0 & 0 & 0 & 0 & 0 & 0.121 & 0 & 0.133 & 0 \\
\hline $\mathrm{X} 4$ & 0 & 0 & 0 & 0 & 0 & 0 & 0 & 0 & 0 & 0 & 0 & 0 & 0 & 0.111 & 0 & 0 & 0 \\
\hline X5 & 0 & 0 & 0 & 0 & 0 & 0 & 0 & 0 & 0 & 0 & 0 & 0 & 0 & 0.116 & 0 & 0 & 0 \\
\hline x6 & 0 & 0 & 0 & 0 & 0.100 & 0 & 0 & 0 & 0 & 0 & 0 & 0 & 0 & 0 & 0 & 0 & 0 \\
\hline $\mathrm{x} 7$ & 0 & 0 & 0 & 0 & 0 & 0 & 0 & 0 & 0 & 0 & 0 & 0 & 0 & 0.112 & 0 & 0 & 0 \\
\hline $\mathrm{x} 8$ & 0 & 0 & 0 & 0 & 0 & 0 & 0 & 0 & 0 & 0.105 & 0 & 0 & 0 & 0 & 0.142 & 0 & 0 \\
\hline X9 & 0 & 0 & 0 & 0 & 0 & 0 & 0 & 0.120 & 0 & 0.106 & 0.109 & 0 & 0 & 0 & 0.150 & 0 & 0 \\
\hline $\mathrm{X} 10$ & 0 & 0 & 0 & 0 & 0 & 0 & 0 & 0.107 & 0 & 0.000 & 0.115 & 0 & 0 & 0 & 0.139 & 0 & 0 \\
\hline $\mathrm{X} 11$ & 0 & 0 & 0 & 0 & 0 & 0 & 0 & 0.119 & 0.103 & 0.101 & 0 & 0 & 0 & 0 & 0.139 & 0 & 0 \\
\hline $\mathrm{X} 12$ & 0 & 0 & 0 & 0 & 0 & 0 & 0 & 0 & 0 & 0 & 0 & 0 & 0.101 & 0 & 0.112 & 0 & 0 \\
\hline $\mathrm{X} 13$ & 0 & 0 & 0 & 0 & 0 & 0 & 0 & 0 & 0 & 0 & 0 & 0 & 0 & 0 & 0.122 & 0 & 0 \\
\hline X14 & 0 & 0 & 0 & 0 & 0 & 0 & 0 & 0 & 0 & 0 & 0 & 0 & 0 & 0 & 0 & 0.118 & 0 \\
\hline $\mathrm{X} 16$ & 0 & 0 & 0 & 0 & 0 & 0 & 0 & 0 & 0 & 0 & 0 & 0 & 0 & 0 & 0 & 0 & 0.106 \\
\hline $\mathrm{X} 17$ & 0 & 0 & 0 & 0 & 0 & 0 & 0 & 0 & 0 & 0 & 0 & 0 & 0 & 0 & 0 & 0 & 0 \\
\hline
\end{tabular}

TABLE 3: Causal influence level summarised of Technology Acceptance Model 3.

\begin{tabular}{|c|c|c|c|c|c|c|c|c|c|c|c|c|c|c|c|c|c|}
\hline $\mathrm{T}$ & $\mathrm{x} 1$ & $\mathrm{X} 2$ & X3 & $\mathrm{X} 4$ & $\mathrm{X} 5$ & $\mathrm{X} 6$ & $\mathrm{X7}$ & $\mathrm{X} 8$ & $\times 9$ & $\mathrm{X} 10$ & X11 & $\mathrm{X} 12$ & $\mathrm{X} 13$ & X14 & $\mathrm{X} 15$ & $\mathrm{X} 16$ & X17 \\
\hline D & 0.975 & 0.212 & 0.354 & 0.111 & 0.116 & 0.180 & 0.112 & 0.247 & 0.485 & 0.361 & 0.462 & 0.213 & 0.122 & 0.118 & 0.222 & 0.106 & 0.000 \\
\hline$R$ & 0.000 & 0.000 & 0.208 & 0.100 & 0.100 & 0.000 & 0.000 & 0.346 & 0.103 & 0.439 & 0.344 & 0.111 & 0.225 & 0.678 & 0.968 & 0.588 & 0.106 \\
\hline$D+R$ & 0.975 & 0.212 & 0.562 & 0.211 & 0.216 & 0.180 & 0.112 & 0.593 & 0.588 & 0.800 & 0.806 & 0.324 & 0.347 & 0.796 & 1.190 & 0.694 & 0.106 \\
\hline$D-R$ & 0.975 & 0.212 & 0.146 & 0.011 & 0.016 & 0.180 & 0.112 & -0.099 & 0.382 & -0.078 & 0.118 & 0.102 & -0.103 & -0.560 & -0.746 & -0.482 & -0.106 \\
\hline
\end{tabular}

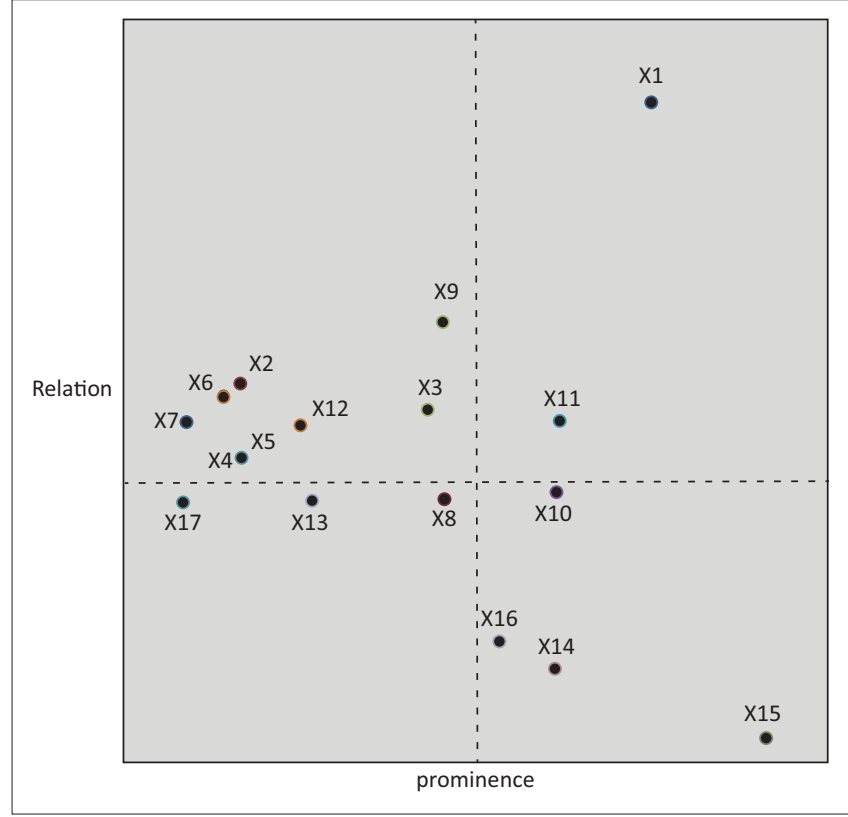

FIGURE 5: 2D causal diagram.

from Equation 6: $R_{3}=0.101+0.107=0.208$. Then, $D_{i}+R_{i}$ is calculated as the prominence, which refers to the total level of the variable affecting others and being affected. $D_{i}-R_{i}$ is calculated as a relation that refers to the gap level of the variable affecting others and being affected. According to the scores, the causal attribute of variables can be obtained. If it is positive, the variable is attributed to a cause attribute, and if it is negative, the variable is attributed to the effect attribute. Taking subjective norm (X3) as an example again: the prominence $\left(D_{3}+R_{3}\right)$ is $0.354+0.208=0.562$ and the relation $\left(D_{3}-R_{3}\right)$ is $0.354-0.208=0.146$. Thus, we next calculated the
$D_{i}$ and $R_{i}$, prominence $\left(D_{i}+R_{i}\right)$, and relation $\left(D_{i}-R_{i}\right)$ of all the TAM3 variables according to Equation 5 and Equation 6 and all the calculation results are summarised in Table 3.

After summing the prominence $\left(D_{i}+R_{i}\right)$ and relation $\left(D_{i}-R_{i}\right)$, we then divided by the 17 variables to obtain the mean, for results respectively of 0.512 and 0.005 . The values can be used to divide the causal matrix into four quadrants, and plot the coordinate scores $\left(D_{k}+R_{k^{\prime}} D_{k}-R_{k}\right)$ of the variables in the $2 D$ causal diagram, as shown in Figure 5.

According to the analysis of Figure 5, considering the interaction influence relationship of TAM3 variables, the variables with high prominence and relation in quadrant I are experience (X1) and computer playfulness (X11), which means these variables have the highest interaction influence level with other variables and are driving factors. Quadrant IV has high prominence but low relation, indicating these variables are core factors: computer anxiety (X10), perceived usefulness (X14), perceived ease of use (X15), and intention to use (X16). Both driving factors and core factors must be solved or managed carefully. Quadrant III has low prominence and low relation: computer self-efficacy (X8), objective usability (X13), and usage behaviour (X17). These variables have the lowest interaction influence level with other variables. Other variables are in quadrant II, with low prominence but high relation: voluntariness $(\mathrm{X} 2)$, subjective norm (X3), image (X4), Job Relevance (X5), Output Quality (X6), Result Demonstrability (X7), Perceptions of External control (X9), and perceived enjoyment (X12). It can be understood from the causal diagram that experience (X1) and computer playfulness (X11) are causal factors that affect thirdparty e-commerce payment service. 
Experience (X1) gave the highest D factor, and directly affected subjective norm (X3) with an influence level of 0.101, computer anxiety (X10) with an influence level of 0.127, computer playfulness (X11) with an influence level of 0.120 , perceived enjoyment (X12) with an influence level of 0.111 , objective usability (X13) with an influence level of 0.124 , and perceived ease of use (X15) with an influence level of 0.164. Experience (X1) directly affected perceived usefulness (X14) with an influence level of 0.114 and directly affected perceived ease of use (X15) with an influence level of 0.114. computer playfulness (X11) directly affects perceived ease of use (X15) with an influence level of 0.139; in addition, computer playfulness (X11) also directly affected computer self-efficacy (X8) with an influence level of 0.119 , perceptions of external control (X9) with an influence level of 0.103 , and computer anxiety (X10) with an influence level of 0.101. The whole structure is shown in Figure 6.

\section{Discussion}

Based on the above-mentioned analysis, most causal relationships relating to TAM3 are in agreement. The variables in the social influence process include experience, voluntariness, image, and subjective norm. Experience (X1) has a significant effect on subjective norm (X3), computer anxiety (X10), computer playfulness (X11), perceived enjoyment (X12), objective usability (X13), and perceived ease of use (X15). Voluntariness (X2) significantly affects subjective norm (X3). Subjective norm (X3) has a significant effect on perceived usefulness (X14) and intention to use (X16). Image (X4) has a significant influence on perceived usefulness (X14). The result shows that for people's acceptance and use of a third-party e-commerce payment, the behaviour intention conforms to TAM3, and is greatly affected by the variables in the social influence process. More specifically, experience (X1) and subjective norm (X3) have greater effects on perceived ease of use (X15) and experience (X1) has greater direct effect on intention to use (X16); therefore, due attention should be paid to the user's experience and feelings for the promotion of a thirdparty e-commerce payment. The advertising effect should be carefully targeted to address these factors.

Some extra causal relationships not present in the TAM3 model were found with the DEMATEL method. Experience (X1) will directly affect perceived usefulness (X14) and intention

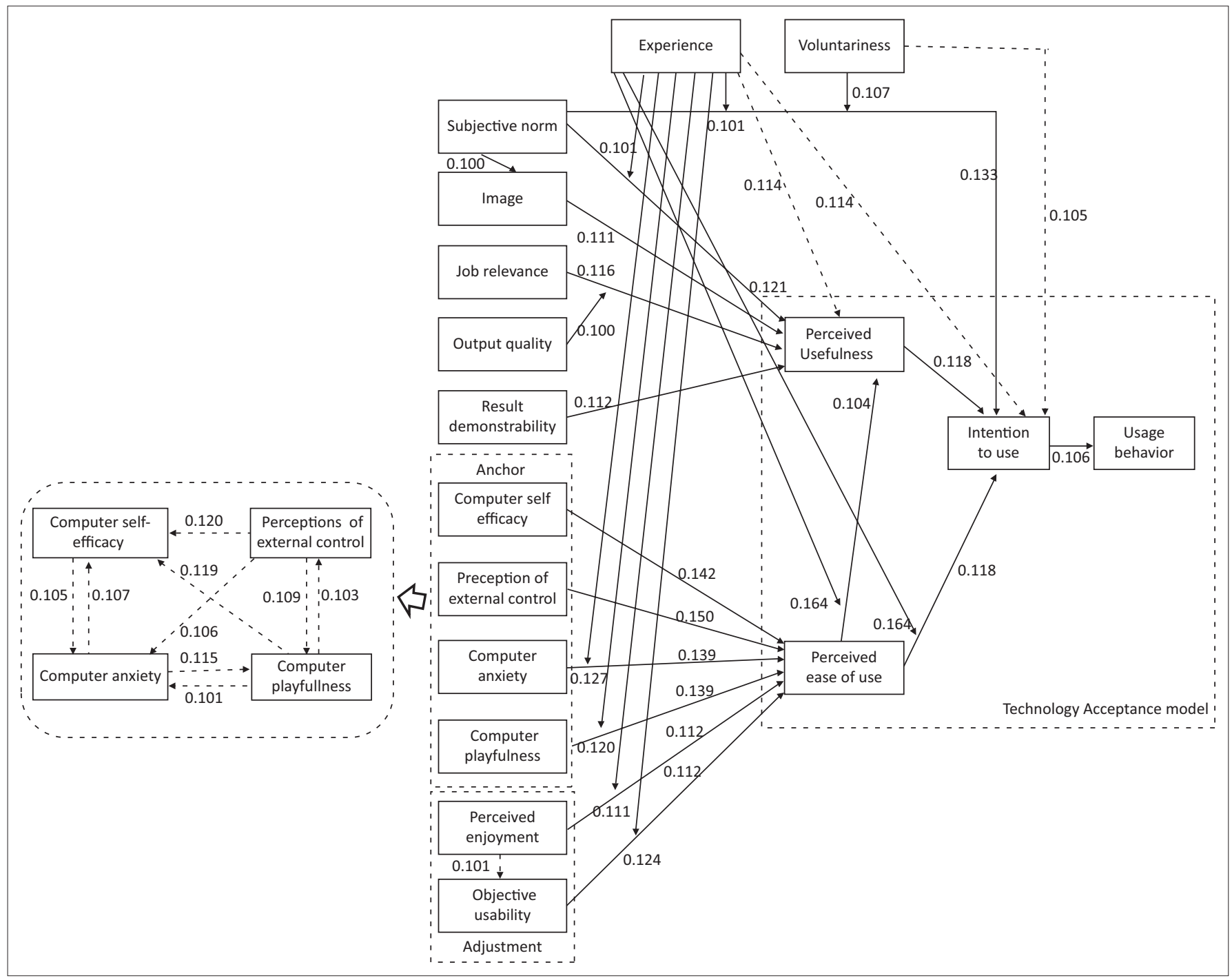

FIGURE 6: Influence structure. 
to use (X16), and voluntariness (X2) will also affect intention to use (X16). This result shows that organisations should pay more attention to people's willingness to use a product to achieve better results. In addition, job relevance (X5) and result demonstrability (X7) have significant effects on perceived usefulness (X14), and output quality (X6) has a significant effect on job relevance (X5). The causal relationships in TAM3 are in agreement. However, the 2D causal diagram of DEMATEL indicates these three variables are in quadrant II, meaning that the variables in the cognitive instrumental process are more independent variables but affect a few other variables. Hence, organisations should enhance the usage interface, usage accessibility, and usage universality to increase behaviour intent.

The variables in Anchors include computer self-efficacy, perceptions of external control, computer anxiety, and computer playfulness. They all show significant influence on perceived ease of use (X15). However, the extra causal relationships were also found but not in the original TAM3. The results show that the variable of Anchors has complex essential interactive relationships, as shown in Figure 6. Hence, when adopting the statistical empirical approach, more attention should be paid to the influence of these four variables on perceived ease of use (X15). Similarly, the variables in Adjustments: perceived enjoyment (X12) will directly affect objective usability (X13).

The major variables of TAM3 include perceived usefulness (X14), perceived ease of use (X15), intention to use (X16), and usage behaviour (X17). The analysis result of DEMATEL shows that the interaction relationships between perceived usefulness (X14), perceived ease of use (X15), intention to use (X16), and usage behaviour (X17) are consistent with the original TAM3 model structure. However, the 2D causal diagram of DEMATEL shows that perceived usefulness (X14), perceived ease of use (X15), and intention to use (X16) are factors of high prominence and low relation, which means that they are greatly affected by other variables.

\section{Conclusion}

TAM3 is a popular model to study the effects of external variables, causal relationships, and the influence level between perceived usefulness, perceived ease of use, and intention to use. This study adopted the DEMATEL method instead of a statistical empirical approach to overcome two important limitations of the TAM3 model: (1) lack of ability to evaluate mutual influence relationships and (2) the requirement of many samples for statistical analysis. By integrating expert opinions, calculations and analysis were used to identify the causal relationships of variables and their influence level of third-party e-commerce payment systems. We found that experience (X1) directly affects computer anxiety (X10), computer playfulness (X11), perceived enjoyment (X12), objective usability (X13), and perceived ease of use (X15). Voluntariness (X2) directly affects subjective norm (X3). Subjective norm (X3) directly affects image (X4), perceived usefulness (X14), and intention to use (X16). Perceived usefulness (X14) is also affected by image (X4), job relevance (X5), result demonstrability (X7), and perceived ease of use (X15). Perceived ease of use (X15) is also affected by computer self-efficacy (X8), perceptions of external control (X9), computer anxiety (X10), computer playfulness (X11), perceived enjoyment (X12), and objective usability (X13). Intention to use (X16) is also affected by perceived usefulness (X14) and perceived ease of use (X15). Intention to use (X16) affects usage behaviour (X17).

However, our study also found extra causal relationships, not present in the TAM3 model, including that experience (X1) will affect perceived usefulness (X14) and intention to use (X16), and that voluntariness (X2) will affect intention to use (X16). Additionally, the Anchor variables have complex interactional relationships, and perceived enjoyment (X12) will affect objective usability (X13). The influence levels of all causal relationships were obtained with the DEMATEL method and the results could aid organisations in formulating marketing plans, improving product quality, or enhancing customer satisfaction. Of course, additional causal relationships and their influence level require further empirical study. This method is complementary to the 2D causal diagram for observing the quadrant of each variable, and exploring which variables are core factors and which are driving factors. Results show that experience (X1) and computer playfulness (X11) are the driving factors of the thirdparty e-commerce payment service, and should be the primary goals in management and marketing. Additionally, the results demonstrate that computer anxiety $(\mathrm{X} 10)$ is the core factor, playing an important role in the promotion of this new technology.

\section{Limitations and future research}

Due to the fact that information from only eight experienced users from three cities and six experts of industry were used in this study, it may lack representative conclusions. Therefore, future research should concentrate on increasing the number of experts and expanding the regional scope. The arithmetic average method was adopted to integrate and collect expert opinions, but may fail to obtain an accurate result. Integration of fuzzy theory could be an alternative direction. In addition, further empirical research can be conducted on additional causal relationships.

\section{Acknowledgements Competing interests}

The author declares that he has no financial or personal relationships that may have inappropriately influenced him in writing this article.

\section{References}

Agudo-Peregrina, A.F., Hernandez-Garcia, A. \& Pascual-Miguel, F.J., 2014, 'Behavioral intention, use behavior and the acceptance of electronic learning systems: Differences between higher education and lifelong learning', Computers in Human Behavior 34, 301-314. https://doi.org/10.1016/j.chb.2013.10.035

Aizen, I. \& Fishbein, M., 1980, Understanding attitudes and predicting social behavior, Prentice-Hall Englewood Cliffs, NJ.

Akman, I. \& Mishra, A., 2015, 'Sector diversity in Green Information Technology practices: Technology Acceptance Model perspective', Computers in Human Behavior 49, 477-486. https://doi.org/10.1016/j.chb.2015.03.009 
Chiu, Y.J., Chen, H.C., Tzeng, G.H. \& Shyu, J.Z., 2006, 'Marketing strategy based on customer behaviour for the LCD-TV', International Journal of Management and Decision Making 7(2), 143-165. https://doi.org/10.1504/IJMDM.2006.009140

Davis, F.D., 1989, 'Perceived usefulness, perceived ease of use, and user acceptance of information technology', MIS Quarterly 13(3), 319-340. https://doi.org/ $10.2307 / 249008$

Davis, F.D. \& Venkatesh, V.A., 1996, 'A critical assessment of potential measurement biases in the technology acceptance model: Three experiments', International Journal of Human-Computer Studies 45(1), 19-45. https://doi.org/10.1006/ ijhc.1996.0040

Dutot, W., 2014, 'Adoption of social media using technology acceptance model the generational effect', International Journal of Technology and Human Interaction 10(4), 18-35. https://doi.org/10.4018/ijthi.2014100102

Fishbein, M. \& Ajzen, I., 1975, Belief, attitude, intention, and behavior: An introduction to theory and research, Addison-Wesley, Reading, MA.

Fontela, E. \& Gabus, A., 1976, The DEMATEL Observer, DEMATEL 1976 Report, Battelle Geneva Research Center, Geneva, Switzerland.

Fu, X.Y., Zhu, Q.H. \& Sarkis, J., 2012, 'Evaluating green supplier development programs at a telecommunications systems provider', International Journal of Production Economics 140, 357-367. https://doi.org/10.1016/j.ijpe.2011.08.030

Gabus, A. \& Fontela, E., 1973, Perceptions of the world problematique: Communication procedure, communicating with those bearing collective responsibility, DEMATEL Report No. 1, Battelle Geneva Research Center, Geneva, Switzerland.

He, D., Lu, Y. \& Zhou, D., 2008, 'Empirical study of consumers' purchase intentions in C2C electronic commerce', Tsinghua Science and Technology 13(3), 287-292. https://doi.org/10.1016/S1007-0214(08)70046-4

Huang, X., Dai, X. \& Liang, W., 2014, 'BulaPay: A novel web service based third-party payment system for e-commerce', Electronic Commerce Research 14, 611-633. payment system for e-commerce', Electronic
https://doi.org/10.1007/s10660-014-9172-1

Irani, Z., Dwivedi, Y.K. \& Williams, M.D., 2009, 'Understanding consumer adoption of broadband: An extension of the technology acceptance model', Journal of the Operational Research Society 60, 1322-1334. https://doi.org/10.1057/ jors.2008.100

Jim, N., 2007, 'Analysis of current E-Payment solution in China-Third Party Payment Platform', IEEE Computer Society, First International Symposium on Data, Privacy and E-Commerce, 406-408.

Lai, V.S. \& Li, H., 2005, 'Technology acceptance model for internet banking: An invariance analysis', Information \& Management 42, 373-386. https://doi. org/10.1016/j.im.2004.01.007

Lee, Y.C., Li, M.L., Yen, T.M. \& Huang, T.H., 2010, 'Analysis of adopting an integrated decision making trial and evaluation laboratory on a technology acceptance model', Expert Systems with Applications 37, 1745-1754. https://doi.org/ 10.1016/j.eswa.2009.07.034

Lin, Y.T., Yang, Y.H., Kang, J.S. \& Yu, H.C., 2011, 'Using DEMATEL method to explore the core competences and causal effect of the IC design service company: An empirical case study', Expert Systems with Applications 38, 6262-6268. https:// doi.org/10.1016/j.eswa.2010.11.092

Maduku, D.K., 2016, 'The effect of institutional trust on internet baking acceptance: Perspectives of South African banking retail customers', South African Journal of Economic and Management Sciences 19(4), 553-548. https://doi.org/10.4102/ sajems.v19i4.1558

Mathu, K. \& Tlare, M.T., 2017, 'The impact of IT adoption in SMEs supply chains: A case of Gauteng and Free State provinces of South Africa', South African Journal of Business Management 48(3), 63-71. https://doi.org/10.4102/sajbm.v48i3.36

Ooi, K.B. \& Tan, W.H., 2016, 'Mobile technology acceptance model: An investigation using mobile users to explore smartphone credit card', Expert Systems with Applications 59, 33-46. https://doi.org/10.1016/j.eswa.2016.04.015

Riemenschneider, C.K., Harrison, D.A. \& Mykytn, P.P. Jr. 2003, 'Understanding IT adoption decisions in small business: Integrating current theories', Information \& Management 40(4), 269-285. https://doi.org/10.1016/S0378-7206(02)00010-1

Szajna, B., 1996, 'Empirical evaluation of revised technology acceptance model', Management Science 42(1), 85-92. https://doi.org/10.1287/mnsc.42.1.85

Tzeng, S., 2014, 'Applying DEMATEL to investigate the relationship between factors affecting parole boards' decision-making in Taiwan', Prison Journal 94(1), 118-136. https://doi.org/10.1177/0032885513512096

Venkatesh, V., 2000, 'Determinants of perceived ease of use: Integrating perceived behavioral control, computer anxiety and enjoyment into the technology acceptance model', Information Systems Research 11, 342-365. https://doi. org/10.1287/isre.11.4.342.11872

Venkatesh, V. \& Bala, H., 2008, 'Technology Acceptance Model 3 and a research agenda on interventions', Decision Sciences 39(2), 273-315. https://doi.org/ 10.1111/j.1540-5915.2008.00192.x

Venkatesh, V. \& Davis, F.D., 2000, 'A theoretical extension of the technology acceptance model: Four longitudinal field studies', Management Science 45(2), 186-204. https://doi.org/10.1287/mnsc.46.2.186.11926

Venkatesh, V., Morris, M.G., Davis, G.B. \& Davis, F.D., 2003, 'User acceptance of information technology: Toward a unified view', MIS Quarterly 27(3), 425-478. https://doi.org/10.2307/30036540

Zhu, D.S., Lin, C.T. \& Hsu, Y.C., 2012, 'Using the technology acceptance model to evaluate user attitude and intention of use for online games', Total Quality Management \& Business Excellence 23(8), 965-980. https://doi.org/10.1080/147 83363.2012.704269 